\title{
HORIZONTAL THERMAL STRUCTURE OF THE MESOSPHERE FROM OBSERVATIONS OF OH(8-3) BAND EMISSIONS
}

\author{
C. A. TEPLEY, R. G. BURNSIDE and J. W. MERIWETHER, JR.
}

Space Physics Research Laboratory, Department of Atmospheric and Oceanic Science, The University of Michigan, Ann Arbor, MI 48109, U.S.A.

(Received 6 May 1981)

\begin{abstract}
Two computerized tilting-filter photometers and a programmable dual axis mirror system have been used to produce maps of $\mathrm{OH}$ rotational temperature and intensity. Each map consists of a square array of 121 sky positions. Significant horizontal structure is not generally observed in mesospheric $\mathrm{OH}(8-3)$ rotational temperature at Arecibo. However, there is evidence for the occasional occurence of a thermal wave just after evening twilight.
\end{abstract}

\section{INTRODUCTION}

Observations of wavelike structure in thermal and surface brightness features of the mesosphere have been reported at a number of observatories using both photometric and photographic techniques (Peterson and Kieffaber, 1975; Moreels and Herse, 1977; Noxon, 1978). These wave features have been attributed to the effect of the lunar atmospheric tide (Peterson, 1979), auroral activity (Chimonas and Hines, 1970) and tropospheric weather systems, to name just a few of a long list of possible causes (Hines, 1974). It should be appreciated that most of the observations were made near mountains at high and mid-latitudes. Krishnamurti (1964) has suggested that gravity waves may be generated by winds blowing over orographic projections in the troposphere. Thus, the nature of the orography near the observing station may influence mesospheric dynamics as the result of the propagation of these waves to higher altitudes. However, there are other ways to generate waves at lower ionosphere altitudes, and any one cause is unlikely to be the sole contributer (Hines, 1972, 1974).

By contrast with the photographic measurements of the $\mathrm{OH}$ infrared surface brightness, photometric observations are usually restricted to a small field of view. Measurements at a fixed position in the sky cannot distinguish between the movement of a wave feature through the field of view of the instrument or a general overall increase and decrease in the airglow brightness. Similarly, an increase in the mesospheric temperature could either be associated with a wave crest or a local 'hot-spot' generated by the turbulent dissipation of energy created by the break- ing of an atmospheric tidal mode (Mathews, 1976; Miller and Smith, 1978). A spatial map of the temperature field is necessary to differentiate between a local transient effect and a moving thermal gravity wave. For mesospheric studies of tides and photochemical mechanisms, the background temporal variation of the temperature throughout the night is interesting and important to the understanding of these effects. Spatial mapping can be used to detect and smooth out temperature variations caused by gravity waves, allowing the underlying temperature fluctuations to be studied in isolation.

Weinstock (1978) has examined the effects of a gravity wave on the $\mathrm{O}_{2}$ and $\mathrm{OH}$ surface brightnesses and rotational temperatures. He applied his results to the $\mathrm{OH}$ and $\mathrm{O}_{2}$ measurements of Noxon (1978) and found that the rotational temperature was a more direct measure of the action of the wave than the airglow intensity. Normally, observations of the $\mathrm{OH}$ surface brightness cannot be directly related to the dynamics of the mesosphere because in situ fuctuations in the densities of atomic hydrogen $(\mathrm{H})$ and ozone $\left(\mathrm{O}_{3}\right)$ will mask the thermal fluctuations introduced by the gravity wave (Noxon, 1978). The wave also affects the rate of the reaction of $\mathrm{H}$ with $\mathrm{O}_{3}$ through the thermal dependence of the rate coefficient.

Spectrometric measurements of the $\mathrm{OH}(8-3)$ rotational temperature were made at Arecibo, in December 1977, in conjunction with a simultaneous incoherent scatter and meteor radar mesopheric wind comparison (Mathews et al, 1981). As Fig. 1 illustrates, these 1977 winter temperatures sometimes showed large variations throughout the night. We have not seen such extreme 


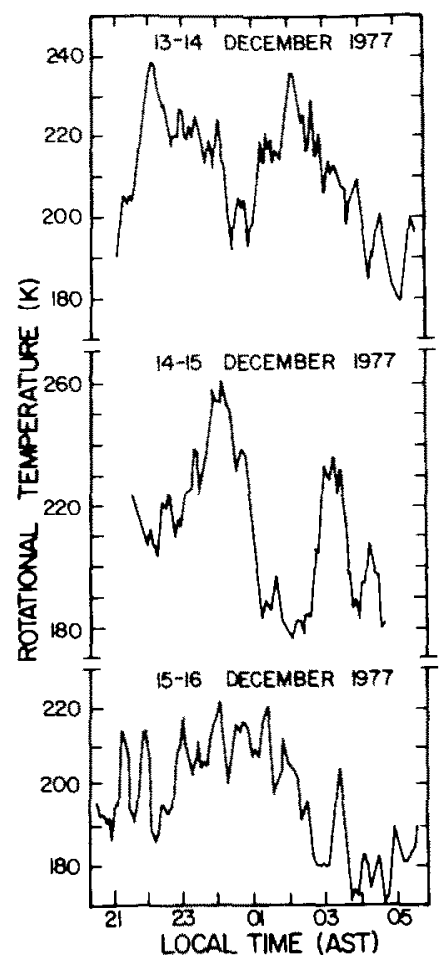

Fig. 1. OH(8-3) BAND ROTATIONAL TEMPERATURE FOR THREE NIGHTS IN.DECEMBER, 1977.

fluctuations in data from other seasons. Stimulated by the possible implications of the thermal behavior shown in Fig. 1, we chose to use the technique of spatial mapping of the $\mathrm{OH}$ rotational temperature to further explore the behavior of the mesosphere over Arecibo in winter. By this method we can use $\mathrm{OH}$ as a tracer agent of the dynamics of the mesosphere.

Our study of the $\mathrm{OH}$ intensity and rotational temperature was based on observations of two $P_{t}$ lines of the Meinel (8-3) band (Meriwether, 1975). A basic assumption with using two rotational lines of the same branch is that the rotational temperature of the molecule is in thermal equilibrium with the temperature of the atmosphere. This is a valid assumption provided that the radiative life time of the rotational state is less than the collision frequency of the mesosphere. Our measurements were made at the airglow facility of the Arecibo Observatory $\left(18.3^{\circ} \mathrm{N}\right.$, $66.7^{\circ} \mathrm{W}$ ). Arecibo is far from mountainous terrain, so these observations will be useful to support or refute the orographic projection hypothesis for wave generation.

\section{INSTRUMENTAL ASPECTS}

The instrument used for these $\mathrm{OH}$ observations comprised of two identical tilting filter photometers (Eather and Reasoner, 1969) having parallel optical axes and mounted under a common dual axis mirror system. Each photometer was equipped with an RCA 31034A photomultiplier selected for red sensitivity. An aspheric lens with a focal length of $12 \mathrm{~mm}$, placed in front of the moisture barrier in the thermoelectric cooler, was used to condense the light onto the photocathode of the tube. At the operating temperature of $-35^{\circ} \mathrm{C}$, the dark level of these photomultipliers was about five counts per second. For the observations of $\mathrm{OH}$, the field of view of the photometers was set at $5^{\circ}$.

Each photometer may contain two filters which are manually selected into the optical path of the instrument. Fitted to the wavelength drive mechanism which tilts the filters is a stepping motor which can be programmed to move the filters with a resolution of 15 motor steps per degree of tilt. The full range of the tilt was $12^{\circ}$ corresponding to a wavelength range of approximately $30 \AA$. Microswitches provide a fiducal mark to identify the filter position of maximum line transmission. These were used to avoid the occasional loss of step synchronization. Additionally, the filter temperature was maintained to within $0.1^{\circ} \mathrm{C}$.

The mirror system is of lightweight aluminium construction with zenith and azimuth axes driven by stepping motors. An HP $9852 \mathrm{~A}$ desktop computer was used to position both the mirrors and the filters and to record data.

The measurements with the photometers were occasionally supplemented by simultaneous spectrometric observations of the rotational temperature of the $\mathrm{OH}(8-3)$ band in the zenith. The $1 \mathrm{~m}$ spectrometer was programmed to scan the rotational lines of the $\mathrm{P}$-branch. The spectrometric measurements provided an additional check on the absolute intensity calibration of the two photometers. Further details regarding the spectrometer are discussed by Meriwether (1979). For the photometric observations, the ratio of $P$ branch intensities was used to calculate the rotational temperature as described by Meriwether (1975). The bandwidth of each filter was determined to within $10 \%$ by recent laboratory calibrations.

The selection of the P-branch lines for the two photometers was governed by the need to maximize the temperature sensitivity while minimizing measurement error. The selection of the $P_{1}(2)$ and $P_{1}(5)$ lines in the $(8-3)$ band is the optimal choice 
(Meriwether, 1975). However, we found the $P_{1}(2)$ line to be sensitive to water vapour absorption, which may be considerable in the humid air of Puerto Rico. Our observations were made chiefly with the $P_{1}(3)$ and $P_{1}(5)$ lines. The $P_{1}(6)$ line was too weak for this application.

To map the $\mathrm{OH}$ rotational temperature field we programmed the mirror system above the two tilting-filter photometers to scan a square array with 121 elements $(11 \times 11)$, with an angular separation between adjacent elements corresponding to a component 'cell' size of 10 or $25 \mathrm{~km}$. This mapping scheme could not be achieved with the spectrometer. The filters were programmed to flip back and forth between line and background positions chosen from prior sequential scans of the $\mathrm{OH}$ rotational lines. We found that an integration time of three seconds per point was adequate for the tropical $\mathrm{OH}$ intensities. About four maps per hour would be generated with 121 elements in each map. Short period waves of $10 \mathrm{~min}$ or less would be missed with this mapping scheme. We estimate an average temperature error of $10 \%$ per data point, but this error varies as a function of the measured intensity (Meriwether, 1975). The cell size of $10 \mathrm{~km}$, which was most of ten used in our observations, was chosen to allow sampling of emitting volumes adjacent to one another without significant gaps or overlapping regions. One rationale for selecting a map scale near $100 \mathrm{~km}$ on a side was based on the $30-70 \mathrm{~km}$ wavelengths of ripples which are often observed in $\mathrm{OH}$ photographs (Peterson and Kieffaber, 1975; Moreels and Herse, 1977).

Because the rotational temperature is a function of the ratio of the intensities of two lines, which are measured with different photometers, we were concerned with the effects of relative sensitivity fluctuations. Unless accounted for by calibration against a standard light source, relative changes in instrumental sensitivity will be erroneously interpreted as a change in the rotational temperature. For this reason, measurements of the response to a ${ }^{14} \mathrm{C}$ source and the dark levels were made every $2 \mathrm{~h}$.

Finally, for the shade maps presented in this paper, some smoothing was applied during their production. We used a five point running average over adjacent cells of the maps.

\section{OBSERVATIONAL RESULTS}

The spatial structure of the $\mathrm{OH}$ rotational temperature was relatively uniform. We examined 15 nights of January and February 1980 and found only one case when wavelike structure was evident. This situation is shown in Fig. 2a where part of the evening of 13-14 January is displayed. It appears that a region of elevated temperature moved across these maps from the SE to the NW between times of 20:00 and 21:17 AST. The horizontal spatial scale of this feature appears to have a wavelength of about $320 \mathrm{~km}$, or twice the diagonal extent of each map. Frederick (1979) estimates that internal gravity waves cause temperature variations (and fluctuations in the minor constituents of the mesosphere) with a horizontal wavelength scale near $360 \mathrm{~km}$. Clearly, our map size was too small to adequately resolve such a wave. However, the example shows that there is very close agreement between this observation and the wavelength scales suggested by Frederick. In Fig. 2b, the corresponding intensity is mapped for the same times as illustrated in Fig. 2a. We see that the variation present in the temperature field is not evident in the maps of $\mathrm{OH}$ intensity, in agreement with the conclusions of Weinstock (1978).

We can estimate the velocity of propagation of the wave pulse. In Fig. $3 a$, we have plotted the average temperature along the $S E$ to NW diagonal for the first eight maps of Fig. 2a. Each curve is shifted from the next by 1.5 cell diagonals or roughly $21 \mathrm{~km}$ horizontal distance. This appears to give the best spatial alignment of the temperature enhancement from one curve to the next. We can assemble by this method a pseudo full period of the wave. We estimate from both Fig. 2 and 3 that this thermal structure was moving at a rate of $23 \mathrm{~ms}^{-1}$, which is reasonable for short period mesospheric gravity waves (Manson et al., 1981). Figure $3 \mathrm{~b}$ gives a better view of the overall enhancement in temperature with the passage of the thermal wave.

Measurements of the hydroxyl emissions were made at Arecibo in other seasons since autumn 1977. We found that the $\mathrm{OH}$ intensity was weaker by a factor of two in winter than in other seasons. Wave events as shown in Fig. 2 were not present. The lack of thermal wave events in our observations must be attributed to the absence of these events rather than to the lack of adequate sensitivity of the technique. We are confident that our sensitivity is sufficient to observe thermal enhancements which are greater than $10 \%$ of the average temperature.

Observations over a wide spatial scale as shown in Fig. 2a enable us to minimize local thermal structure by averaging the temperature over the 


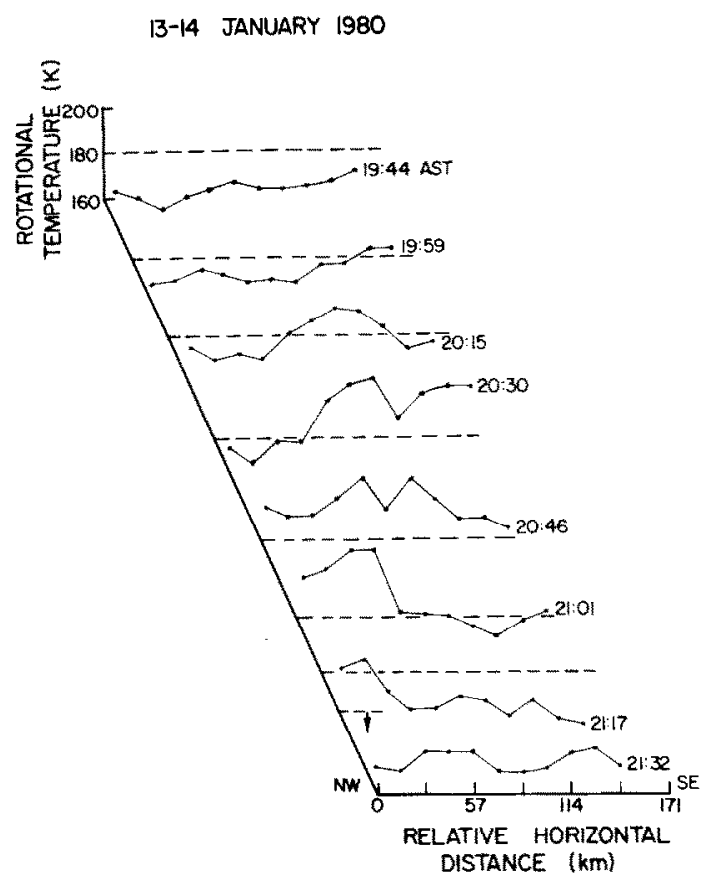

(a)

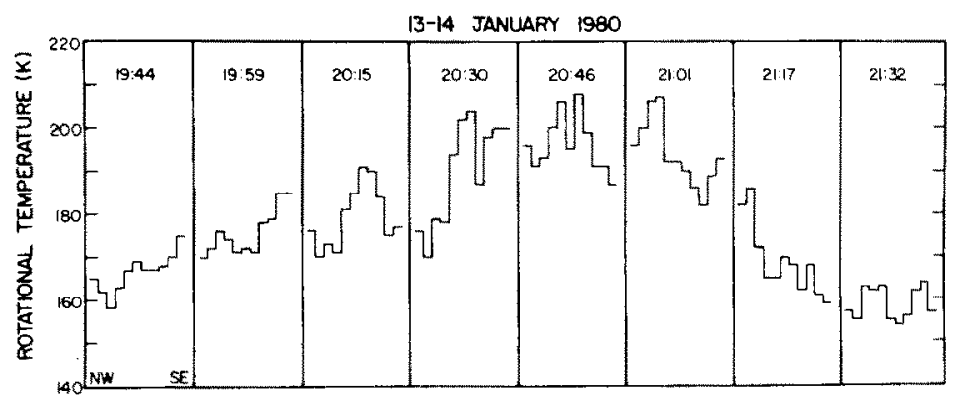

(b)

Fig, 3. The average temperature across the SE to NW diagonal. for the first eight Maps of Fig. 2a. EACH CURVE, DISPLA YFD IN (a), IS SHIFTFD FROM THF NFXT BY AROUT $21 \mathrm{~km}$ HORIZONTAL, DISTANCE (SEE TEXT). PART (b) DEMONSTRATES THE OVERALL TEMPERATURE ENHANCEMENT AS A RESULT OF THE PASSAGE OF THE THERMAL. WAVE.

entire map into a single value. We have done this for a few winter nights in 1980, and the results are shown in Fig. 4a. The corresponding intensities of the $\mathrm{OH} \mathrm{P}_{1}(5)$ line are presented in Fig. 4b. The average temperatures of Fig. 4a show substantial variations, sometimes as much as $50^{\circ} \mathrm{K}$ on any given night (see e.g. 14-15 January). Except for 13-14 January, variations such as these are characteristic of an overall evening cooling and early morning heating of the region, as demonstrated by the temperature map for 14-15 January in Fig. 5. However, the nights of 13-14 and 14-15 January do not exhibit marked differences in the way their average temperature varies. That is, the average temperature variation on these nights is similar, although the tempcrature maps for the two nights are different. Clearly, the mapping technique has considerable potential for resolving differences between long and short period waves.

\section{SUMMARY AND CONCLUSIONS}

Wave features such as the one illustrated in Fig. 2 do not appear to be a common phenomenon of the mesosphere at Arecibo. From 15 attempts to detect these winter fluctuations in the $\mathrm{OH}$ temperature, only the event on 13-14 January was 
13-14 JANURRY 1980

(A) Rotational temperatuRe $\left(170-270^{\circ} \mathrm{K}\right)$

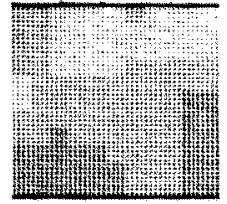

1944

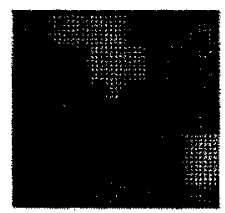

2046

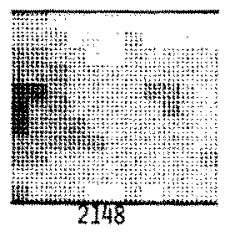

(B) P1 (5) INTENSITY

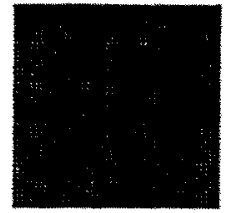

1944

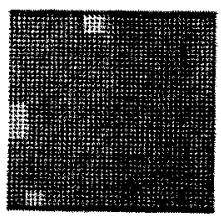

2046

॥

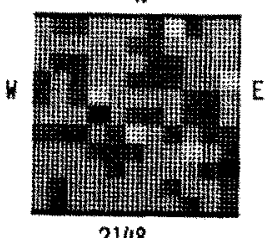

2148

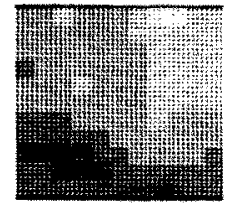

2000

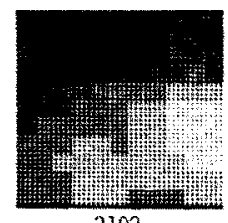

2102

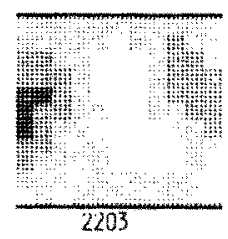

$(0-25)$

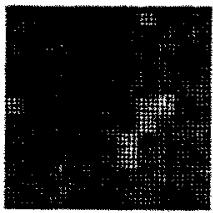

2000

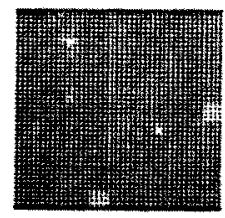

2102

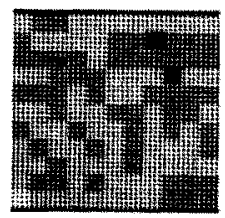

2203

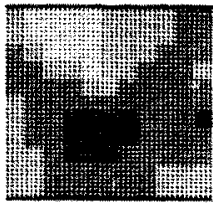

2015
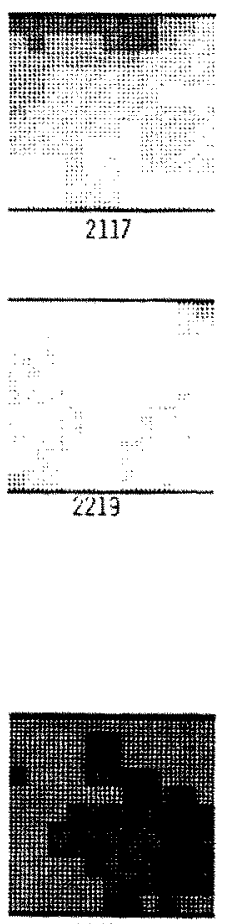

2015

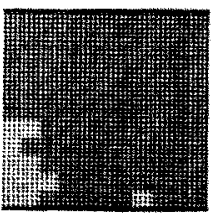

2117

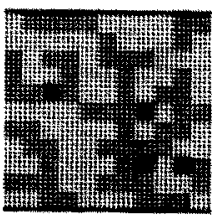

2219
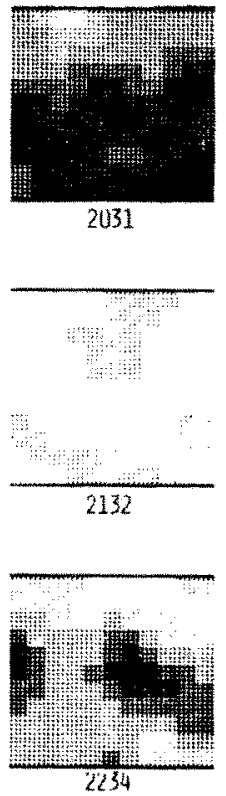

2031

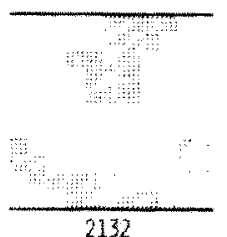

2132

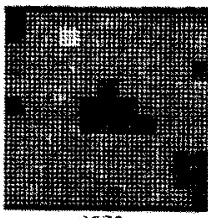

2031

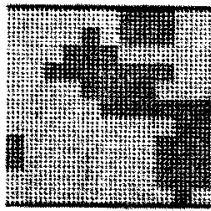

2132

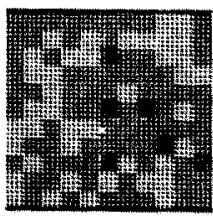

2234

FiG. 2. SHADE MAPS FOR PART OF THE EVENING OF 13-14 J ANUARY 1980. BOTH TEMPERATURE (a) AND P (5) LINE INTENSITY (b) ARE MAPPED FOR SEVEN leVELS OF SHADE. DARKER AREAS REPRESENT REGIONS OF HIGHER TEMPERATURE WHERE THE RANGE EXTENOS FROM $170^{\circ} \mathrm{K}$ FOR ALL WHTTE AREAS TO $270^{\circ} \mathrm{K}$ FOR SOI ID BLACK. THE CORRESPONDING INTENSITY RANGE EXTENDS FROMO TO 25R. THE HORITONTAL SCAI.F FOR F.ACH MAP IS $110 \mathrm{Km}$ ON A SIDE. 
14-15 JanuarY 1980

(A) Rotational temperature $\left(140-250^{\circ} \mathrm{K}\right)$

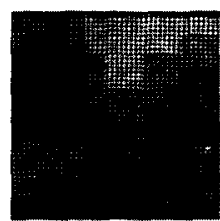

2037

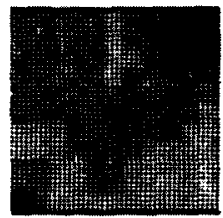

2141

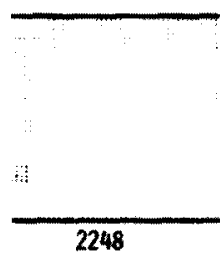

2248

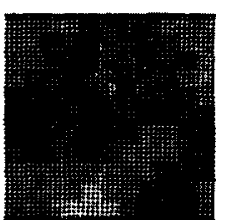

2053

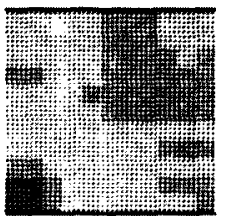

2202
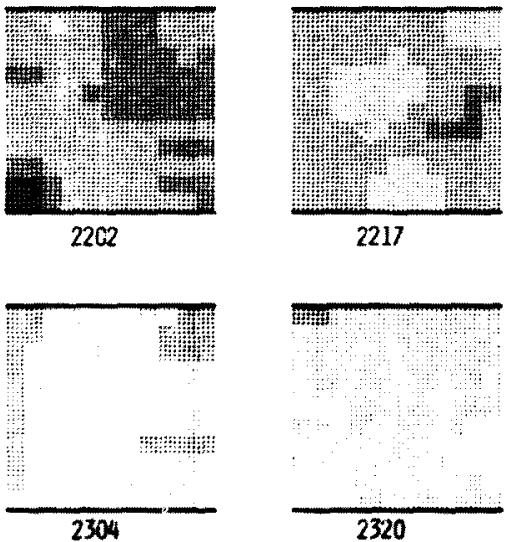

2217

2108

2124

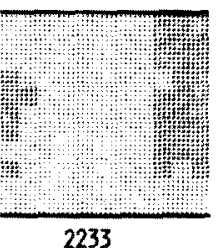

2233

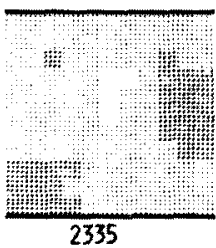

(B) $P_{1}$ (5) INTENSITY $(0-25 R)$

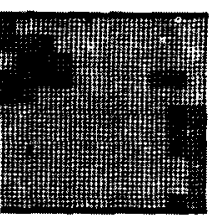

2037

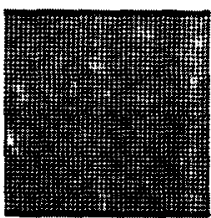

2141

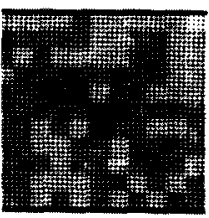

2248

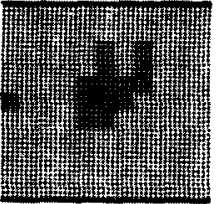

2053

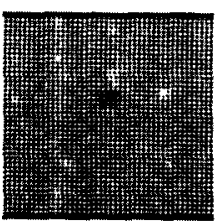

2208

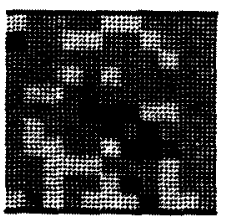

2304

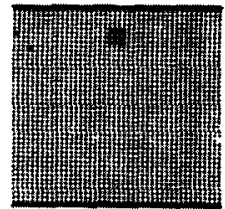

2108

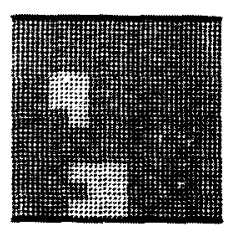

2217

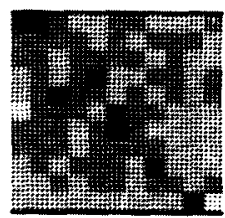

2320

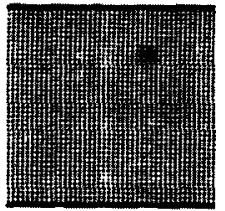

2124

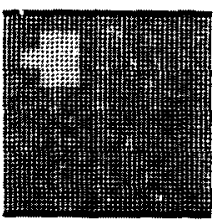

2233

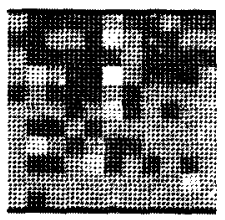

2335

Fig. 5. SAme as Fig. 2 but for 14-15 January 1980. 


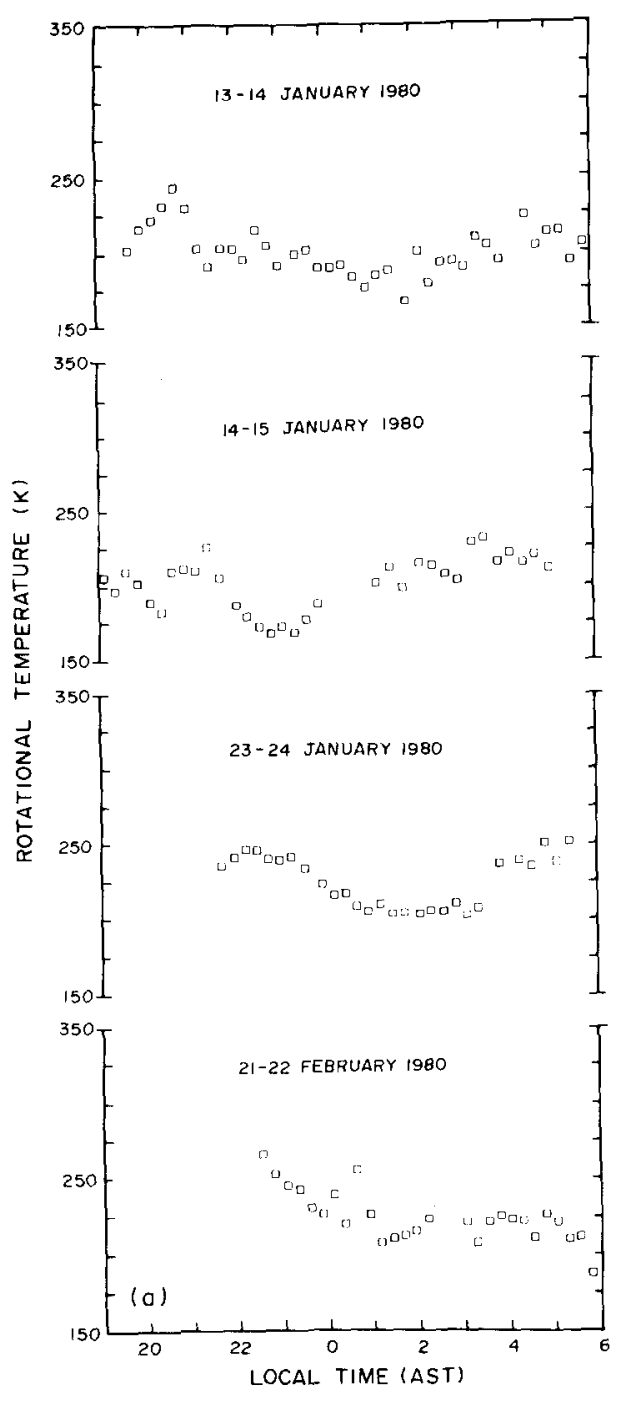

(a)

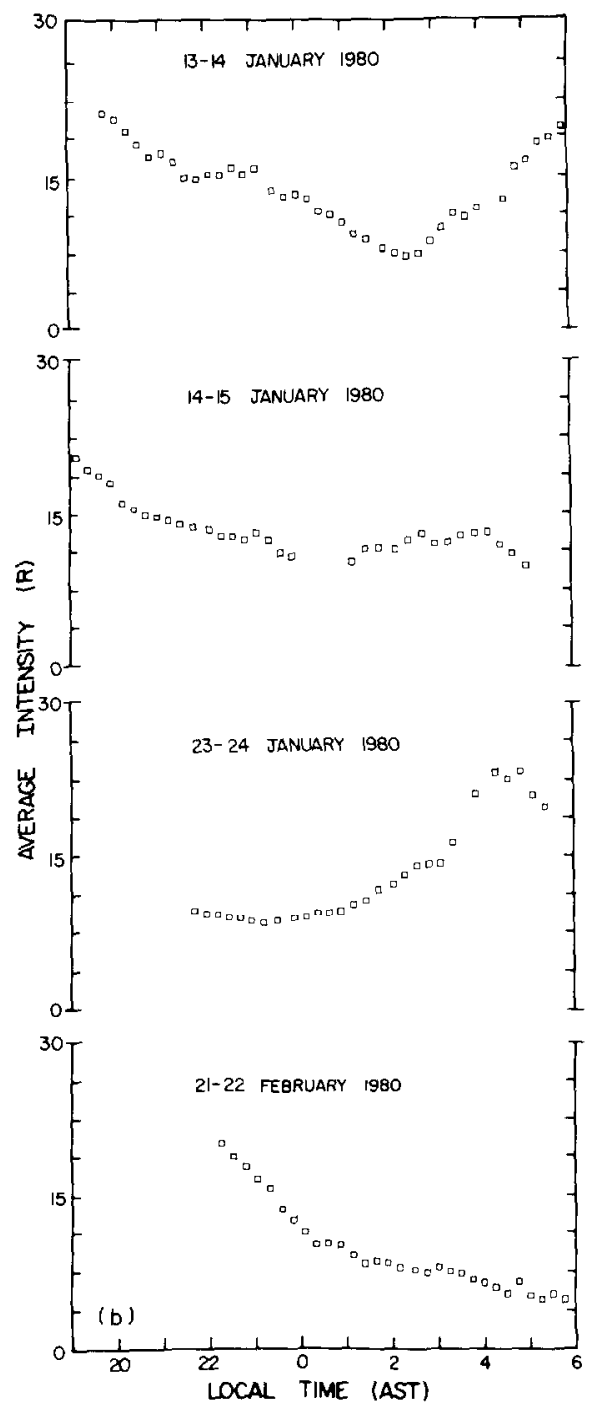

(b)

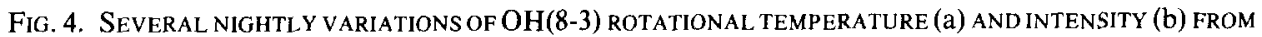
JANUARY AND FEBRUARY, 1980. THESE TEMPERATURES AND INTFNSITIF.S ARF. THF. AVERAGF OF INDIVIDUAL SHADE MAPS AS THE ONES SHOWN IN FIGS 2 AND 5. THE STANDARD DEVIATION OF THE MEAN TEMPERATURE IS TYPICALLY $\pm 3 \mathrm{~K}$.

found. For observatories located near mountains, gravity wave features appear more frequently in the airglow (Krassovsky and Shagaev, 1977; Noxon, 1978). Although the statistics are not well known, the frequency of occurrence appears to be in the range of $15-20 \%$. Additionally, the work of Lilly and Kennedy (1973) and Lilly and Lester (1974) show that there is an enhancement in the amount of atmospheric turbulence over mountains. Orographic projection into the lower atmosphere may be a significant mechanism res- ponsible for generating the waves as air currents pass over the mountains. If this were the case, then we would not expect to find such wave features at Puerto Rico. Beer (1973) suggested that the motion of the shadow cast by the Earth into the atmosphere during sunset can generate acoustic gravity waves (see also Beer, 1978). These waves have been detected by Raitt and Clark (1973) in electron temperature measurements by satellite. Because the wave feature of Fig. 2 occurs soon after sunset, Beer's mechanism may provide a more 
plausible explanation for our observations on 1314 January. But, we might expect this mechanism to generate post-sunset waves in a larger portion of $\mathrm{OH}$ data than we have found.

Observations of the type presented in this report are useful for supplementing other instruments more sensitive to the vertical structure of the mesosphere, such as the incoherent scatter or meteor radars. For example, meteor radar wind data from August and December 1977 show evidence of long period waves as well as the 12 and $24 \mathrm{hr}$ components present at mesospheric altitudes (J. C. G. Walker, 1978, private communication). The temperature would be in phase with, say, the southward wind if the tide was purely diurnal (Mathews, 1976). However, this definite phase relation would not be present for mixtures of different tides (or of modes of the same tide) as are often observed in the winter mesosphere (Glass and Fellous, 1975). This would suggest that the fluctuations illustrated in Fig. 1 are the result of such tidal mixtures to produce the effect shown. The fluctuations most often seen in Arecibo $\mathrm{OH}$ data are probably tidal effects and are not due to the passage of gravity waves, even though both offer the same appearence in the temporal variation of the average temperature.

The technique of spatial averaging produce maps of mesospheric temperature in which the tidal variations are clarified, because local or shorter period fluctuations can be identified and smoothed out. It is not necessary to employ more complicated time filtering techniques often used in tidal analysis of airglow data (Teitelbaum and Petitdidier, 1978). An additional advantage of mapping mesospheric temperatures rather than the $\mathrm{OH}$ surface brightness is that complications introduced by atmospheric extinction or the van Rijin effect are avoided.

Maps of $\mathrm{O}_{2}(0-1)$ band emissions or OI(5577 $\left.\AA\right)$ kinetic temperatures made in conjunction with the $\mathrm{OH}$ observations will show whether there is coupling of wave motion between the two altitude regions of 97 and $85 \mathrm{~km}$, where these two separate emissions originate (Noxon, 1978). A phase difference in the temperature variations is expected because of the relatively short vertical wavelength of a gravity wave compared with the altitude separation of the two emissions. However. if the thermal fluctuations originate from tides, which would have longer vertical wavelengths, the phase shift would be reduced and dynamical thermal and chemical processes will take place nearly simultaneously at the heights of the $\mathrm{OH}$ and
$\mathrm{O}_{2}$ emissions. We intend to study the possible correlations between mesospheric temperature maps of $\mathrm{OH}$ and $\mathrm{O}_{2}(0-1)$ or $\mathrm{OI}(5577 \AA)$ emissions in our future investigations.

Acknowledgements-We wish to thank the staff of the Arecibo Observatory for their assistance during the duration of these experiments. The Arecibo Observatory is operated by Cornell University under contract with the National Science Foundation. Partial support for this work was provided by a NASA Grant NAGW-32.

\section{REFERENCES}

Beer, T. (1973). Supersonic generation of atmospheric waves. Nature $242,34$.

Beer, T. (1978). On the atmospheric wave generation by the terminator. Planet. Space Sci. 26, 185-188.

Chimonas, G. and Hines C. O., (1970). Atmospheric gravity waves launched by auroral currents. Planet. Space Sci. 18, 565-582.

Eather, R. H. and Reasoner D. L., (1969). Spectrophotometry of faint light sources using a tilting-filter photometer. App. Opt. 8, 227-242.

Frederick, J. E. (1979). Influence of gravity wave activity on lower thermospheric photochemistry and composition. Planet. Space Sci. 27, 1469-1477.

Glass, M. and Fellous, J. L. (1975). The eight-hourly (ter-diurnal) component of atmospheric tides. Space Res. 15, 191-197.

Hines, C. O. (1972). Motions in the ionospheric D and E regions. Phil. Trans. $R$. Soc. Lond. A271, 457-471.

Hines, C. O. (1974). The Upper Atmosphere in Motion, pp. 659-660. American Geophysical Union, Washington, D.C.

Krishnamurti, T. N. (1964). Theory of two-dimensional mountain waves. Rev. Geophys. 2, 593-624.

Lilly, D. K. and Kennedy, P. J. (1973). Observations of a stationary mountain wave and its associated momentum flux and energy dissipation. $J$. Atmos. Sci. 30, $1135-1152$.

Lilly, D. K. and Lester, P. F. (1974). Waves and turbulence in the stratosphere. J. Atmos. Sci. 31, 800-812.

Manson, A. H., Meek, C. E., and Gregory, J. B. (1981). Gravity waves of short period $(5-90 \mathrm{~min})$ in the lower thermosphere at $52^{\circ} \mathrm{N}$ (Saskatoon, Canada); 1978/1979. J. atmos. terr. Phys. 43, 35-44.

Mathews, J. D. (1976). Measurements of the diurnal tides in the 80 - to $100-\mathrm{km}$ altitude range at Arecibo. $J$. geophys. Res. 81, 4671-4677.

Mathews, J. D., Sulzer, M. P., Tepley, C. A., Bernard, R., Fellous, J. L., Glass, M., Massbeauf, M., Ganguly, S., Harper, R. M., Behnke, R. A. and Walker J. C. G. (1981). A comparison between Thomson scatter and meteor radar wind measurements in the $65-105 \mathrm{~km}$ altitude region at Arecibo. Planet. Space Sci. 29, 345348 .

Meriwether, J. W., Jr. (1975). High latitude airglow observations of correlated short-term fluctuations in the hydroxyl Meinel 8-3 band intensity and rotational temperature. Planet. Space Sci. 23, 1211-1221.

Meriwether, J. W., Jr. (1979). Measurement of weak airglow emissions with a programmable scanning spectrometer. Planet. Space Sci. 27, 1221-1232. 
Miller, K. L. and Smith, L. G. (1978). Incoherent scatter radar observations of irregular structure in mid latitude sporadic E layers. J. geophys. Res. 83, 3761-3775.

Moreels, G. and Herse, M. (1977). Photographic evidence of waves around the $85 \mathrm{~km}$ level. Planet. Space Sci. 25 , 265-273.

Noxon, J. F. (1978). Effect of internal gravity waves upon night airglow temperatures. Geophys. Res. Let. 5 , 25-27.

Peterson, A. W. (1979). Airglow events visible to the naked eye. App. Opt. 18, 3390-3393.
Peterson, A. W. and Kieffaber, L. M. (1975). Photography and photometry of the near infrared $\mathrm{OH}$ airglow. Nature 257, 649-650.

Raitt, W. J. and Clark, D. H. (1973). Wave-like disturbances in the ionosphere. Nature 243, 508-509.

Teitelbaum, H. and Petitdidier, M. (1978). Night-time variation of short period fluctuations $(2-15 \mathrm{~min})$ in the oxygen green line. J. atmos. terr. Phys. 40, 223-227.

Weinstock, J. (1978). Theory of the interaction of gravity waves with $\mathrm{O}_{2}\left({ }^{\prime} \Sigma\right)$ airglow. J. geophys. Res. 83, 51755185. 